Supporting Information

\title{
A Plant Leaf-Mimetic Membrane with Controllable Gas Permeation for Efficient Preservation of Perishable Products
}

Zhiqiang Zhou ${ }^{1 \S}$, Jinju $\mathrm{Ma}^{1 * \S}$, Kun $\mathrm{Li}^{1}$, Wenwen Zhang ${ }^{1}, \mathrm{Kai} \mathrm{Li}^{2 *}$, Xinghao $\mathrm{Tu}^{3}$, Lanxiang $\mathrm{Liu}^{1}$, Juan $\mathrm{Xu}^{1}$, Hong Zhang ${ }^{1 *}$

${ }^{1}$ Research Institute of Resources Insects, Chinese Academy of Forestry, 650233, Kunming, China

${ }^{2}$ Faculty of Chemical Engineering, Kunming University of Science and Technology, 650500, Kunming, China

3 South Subtropical Crop Research Institute, Chinese Academy of Tropical Agricultural Science/Key Laboratory of Tropical Fruit Biology, Ministry of Agriculture, Guangdong, Zhanjiang, 524091, China

$\S$ These authors contributed equally.

Corresponding author: Jinju Ma (majinjuchem@163.com), Kai Li (lkjnkmwh@hotmail.com) and Hong Zhang (kmzhh@hotmail.com). 


\section{Solvent อvตอortion method}

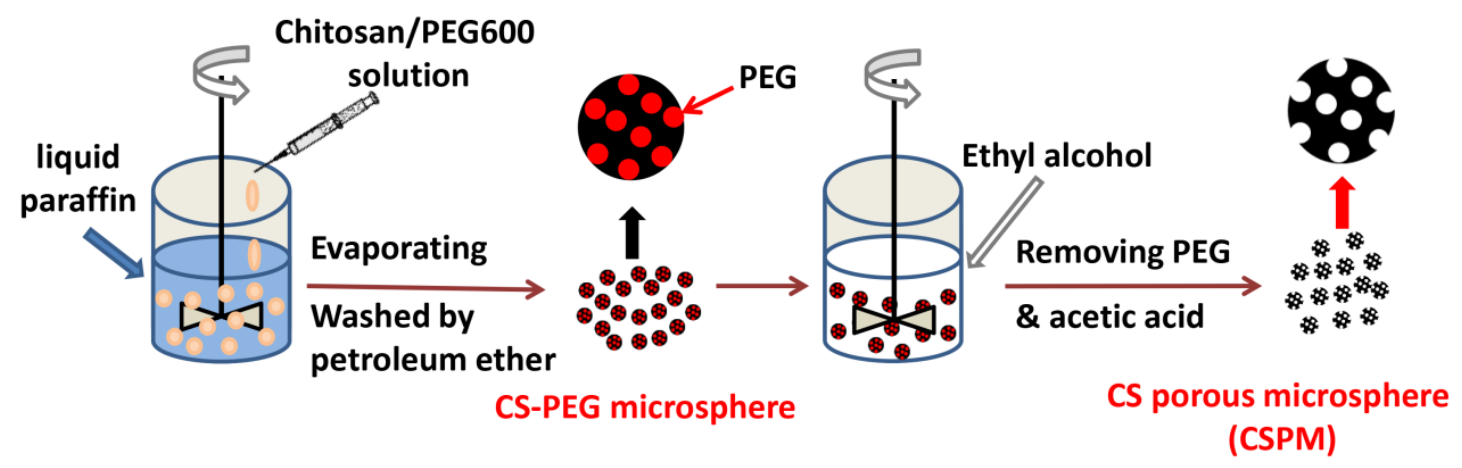

\section{TIPS method}
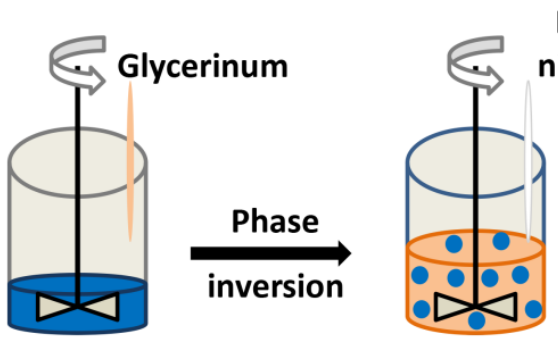

Liquid nitrogen
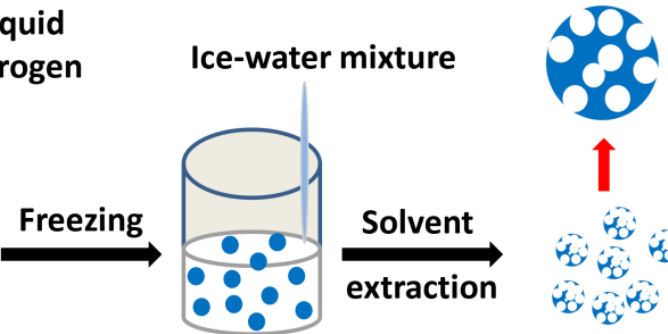

PLLA porous microsphere

(PPM)

Figure S1. Scheme of fabrication of chitosan porous microspheres (up) and

PLLA porous microspheres (down). The chitosan and PLLA porous microspheres were prepared by the solvent evaporation method and thermally induced phase separation method, respectively.

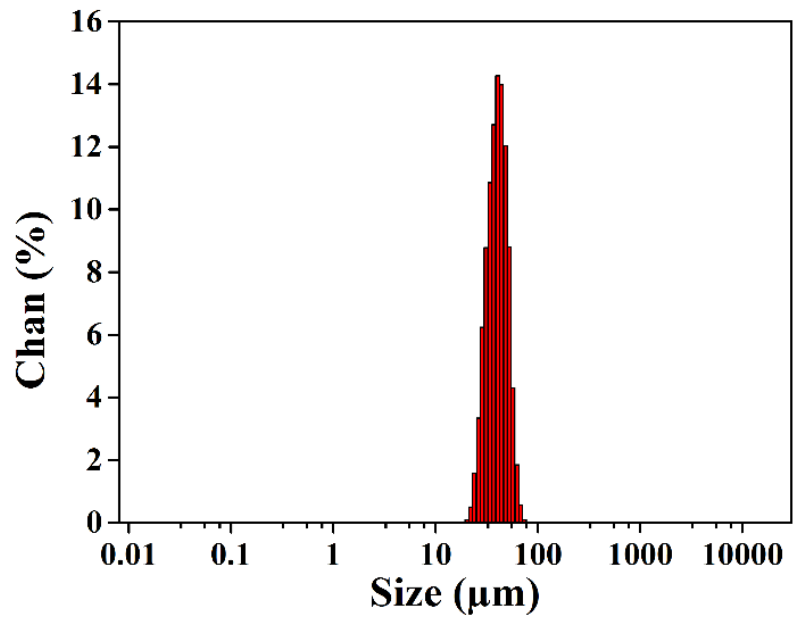

Figure S2. Particle size distribution of chitosan porous microspheres (CSPMs). 

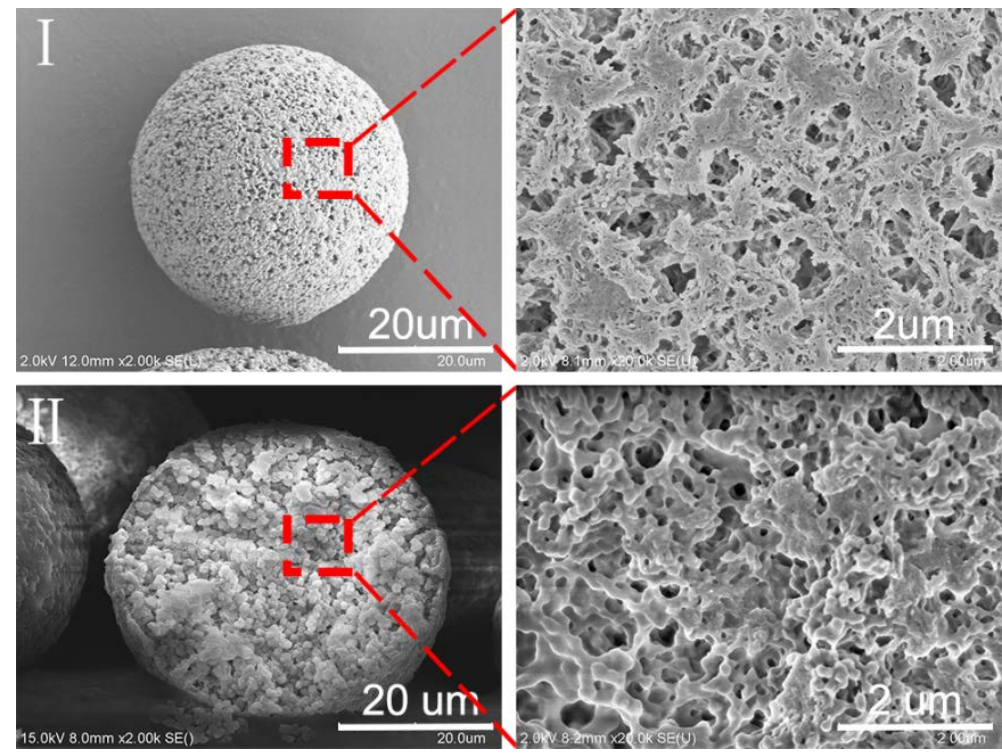

Figure S3. SEM images of a representative chitosan porous microsphere ( I ), and corresponding cross-section ( II ) of the porous chitosan microsphere, showing abundantly porous structure.
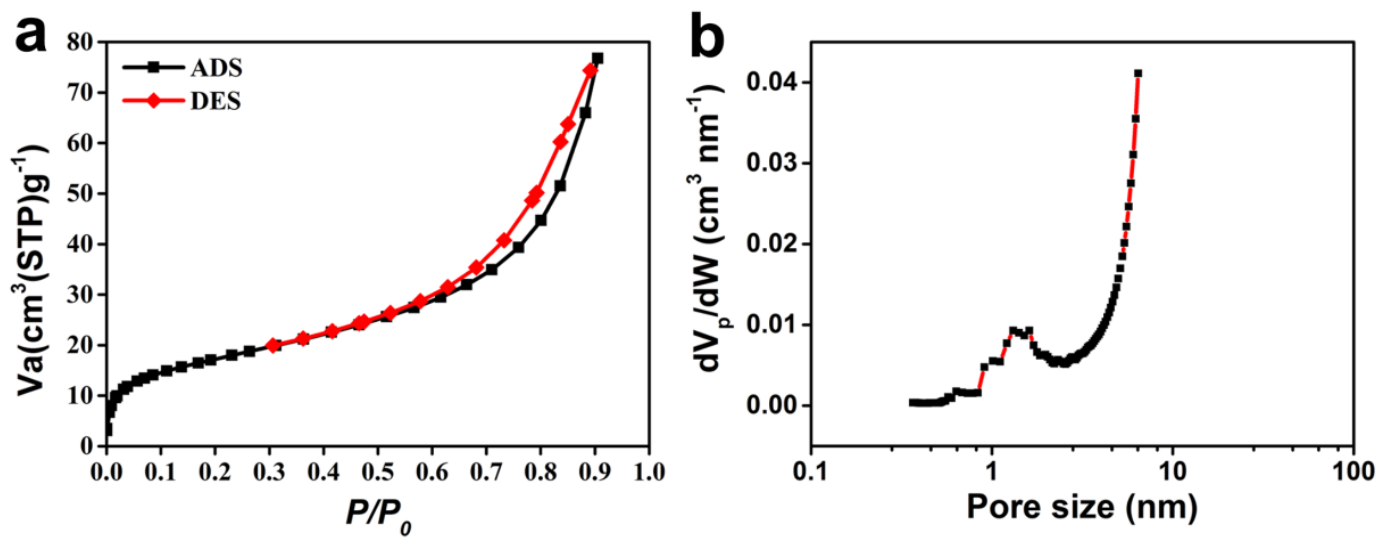

Figure S4. a) Nitrogen gas adsorption and desorption isotherms for CSPM. The nitrogen gas adsorption and desorption isotherms for CSPM reveals that the adsorption type matched the typical IV adsorption isotherms model, which means that the pore size distribution is mesoporous. b) The pore size distribution of CSPM, using NLDFT \& GCMC method analysis. 

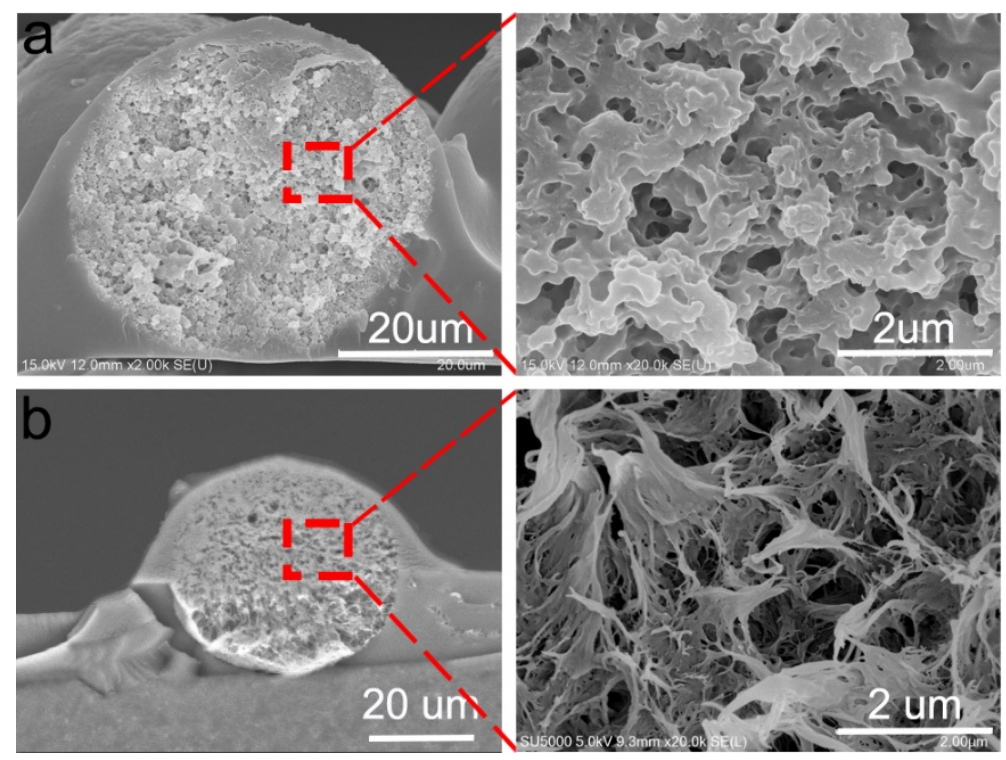

Figure S5. SEM images of cross-section of CSPM/shellac (a) and PPM/shellac (b) membranes. 


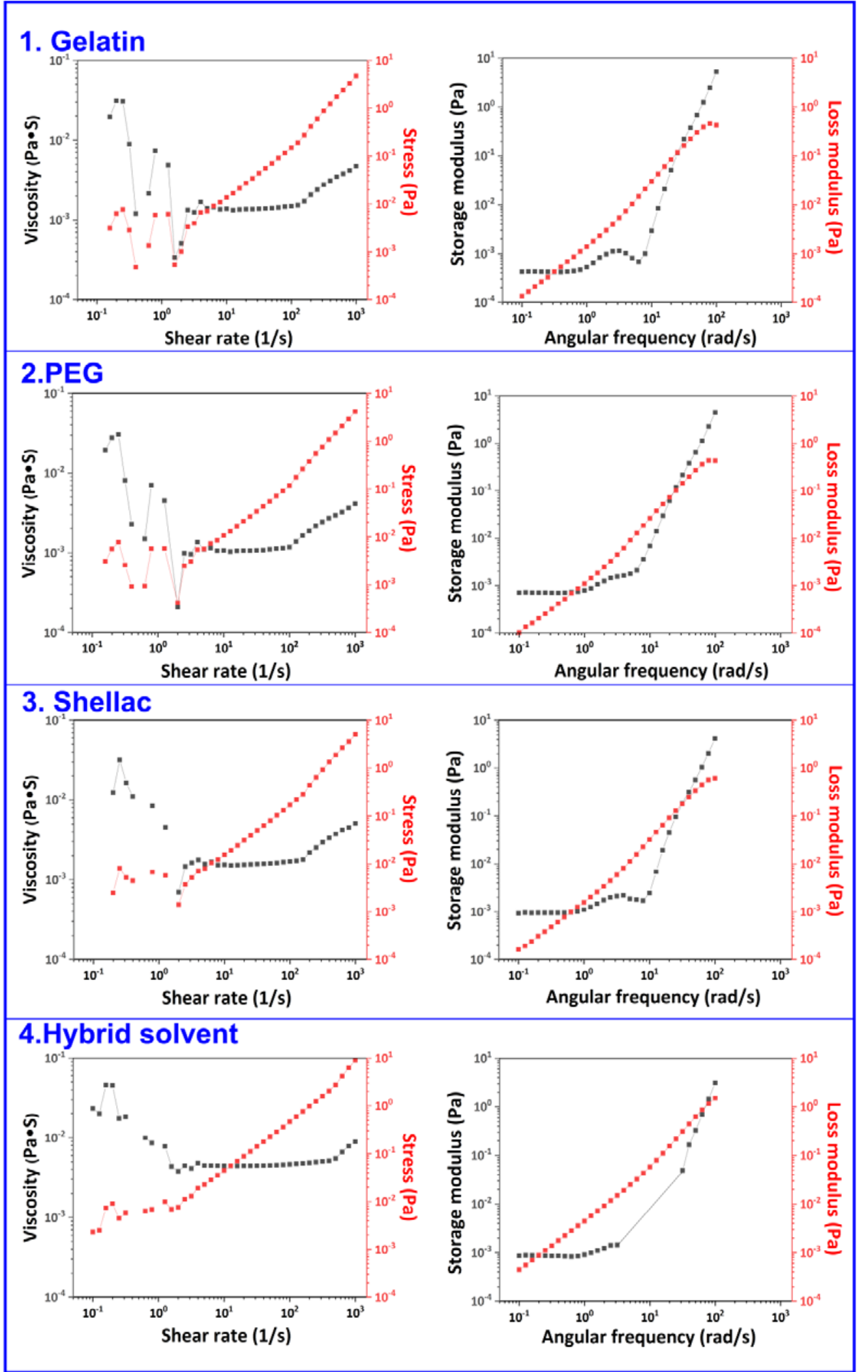

Figure S6. The rheology behavior of the PEG (2 wt\%), gelatin (0.8 wt\%), shellac (8 $w t \%)$ and hybrid solvent (PEG (2 wt\%) + gelatin (0.8 wt\%) + shellac (8wt\%)) 


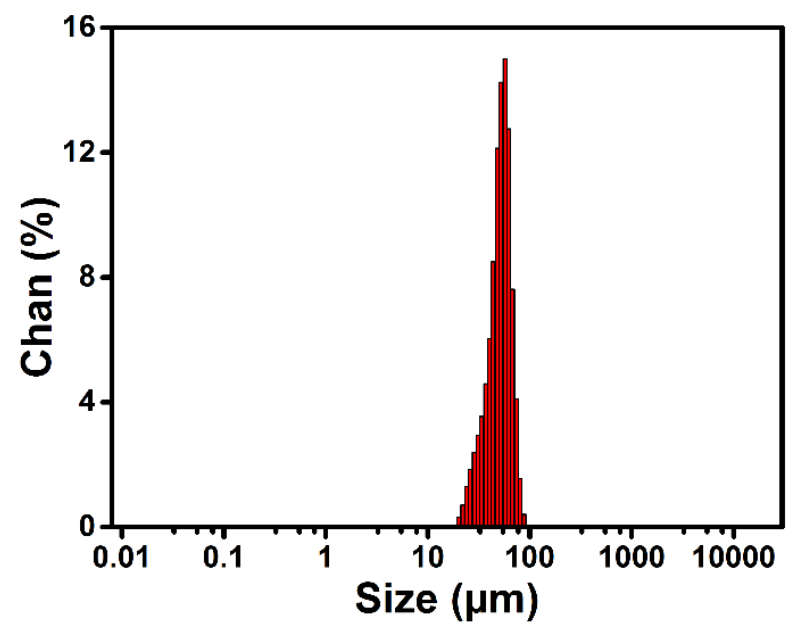

Figure S7. Particle size distribution of chitosan solid interior microspheres (CSMs).
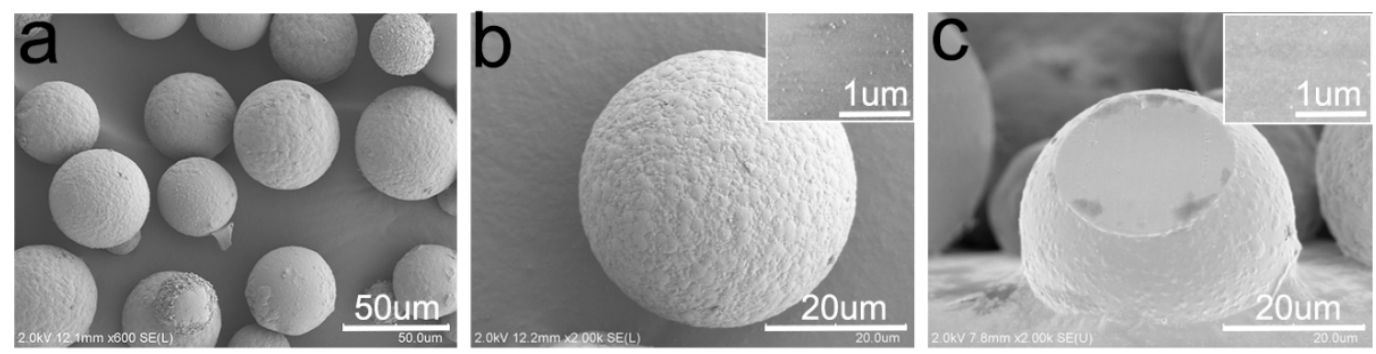

Figure S8. SEM images of surface and cross-section of CSM, showing the smooth surface of the microspheres.

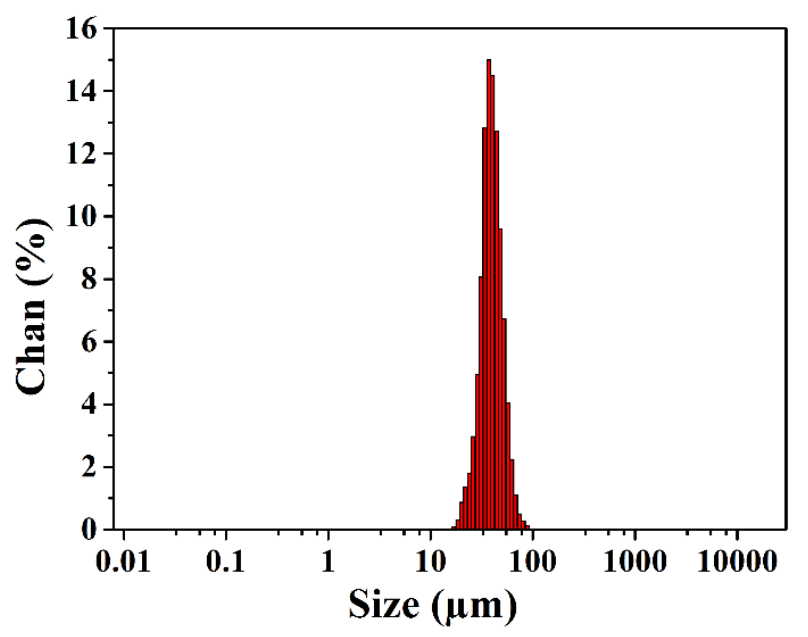

Figure S9. The particle size distribution of PLLA porous microspheres (PPMs). 

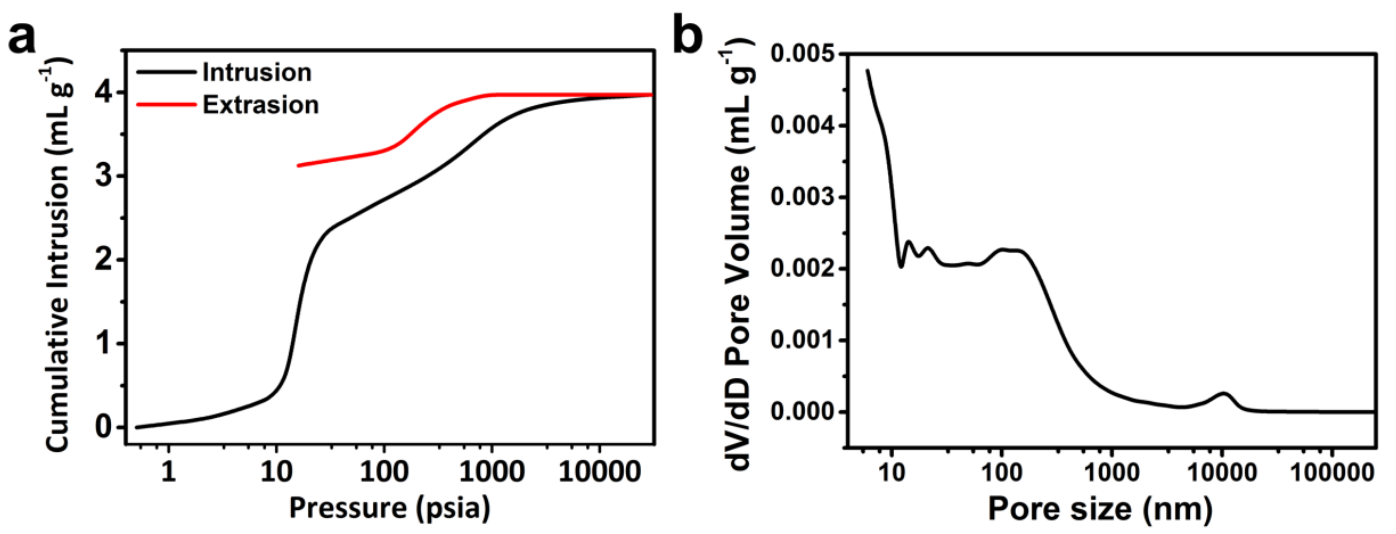

Figure S10. a) The cumulative intrusion vs pressure of PPM, using mercury intrusion method analysis. b) The pore size distribution of PPM, using mercury intrusion method analysis.

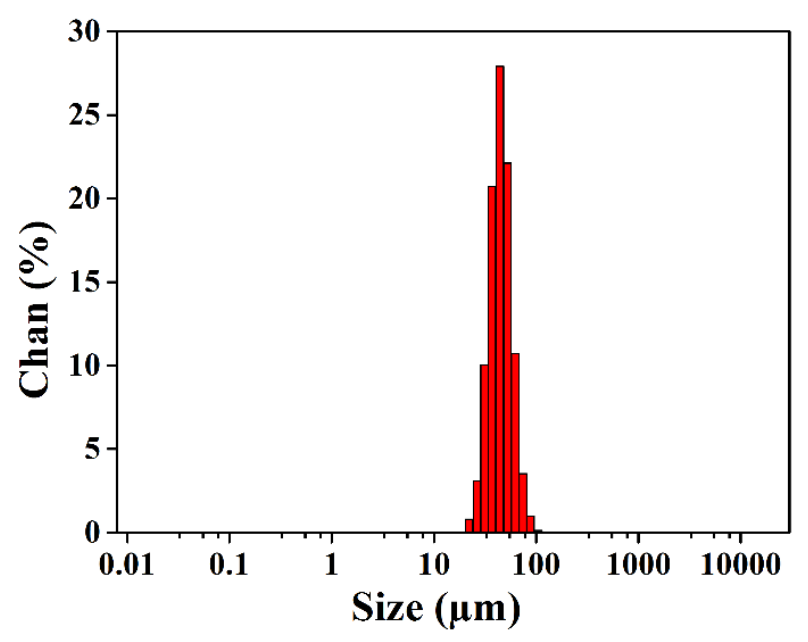

Figure S11. The particle size distribution of PLLA solid interior microspheres (PMs).
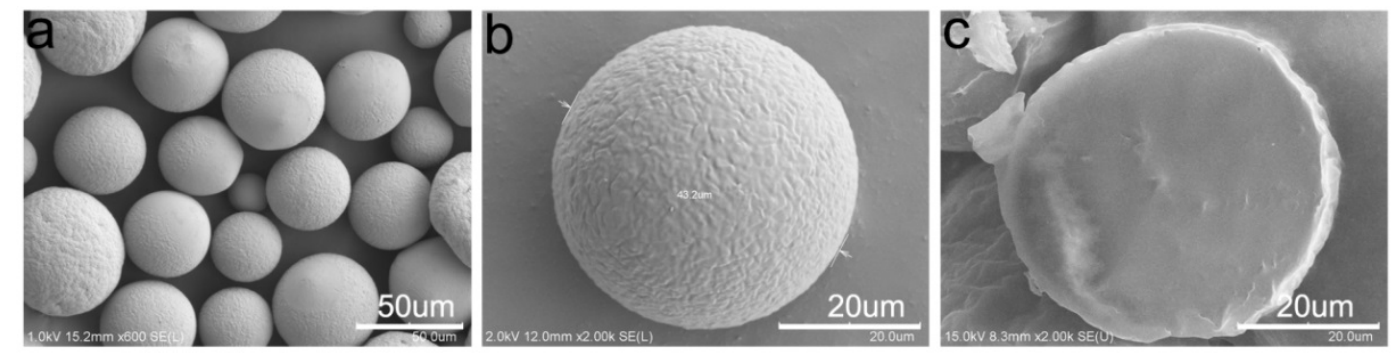

Figure S12. SEM images of surface and cross-section of PM, showing the smooth surface of the microspheres. 


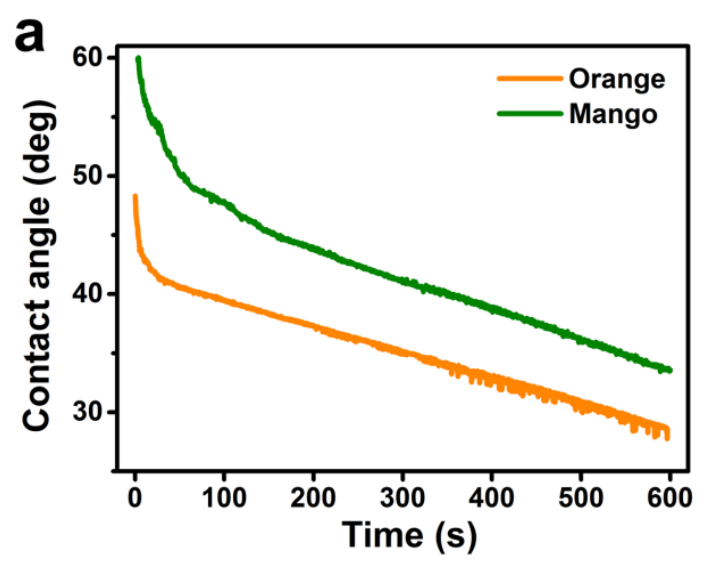

b
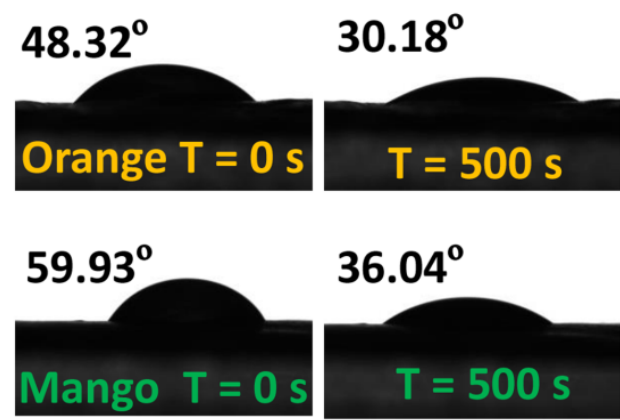

$36.04^{\circ}$

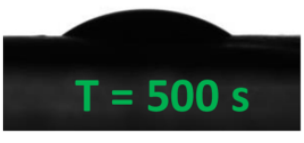

Figure S13. a) Contact angle of the shellac coating on orange and mango peels with time. b) Optical images of contact angle of shellac coating on orange and mango peels at $\mathrm{t}=0$ and $\mathrm{t}=500 \mathrm{~s}$.
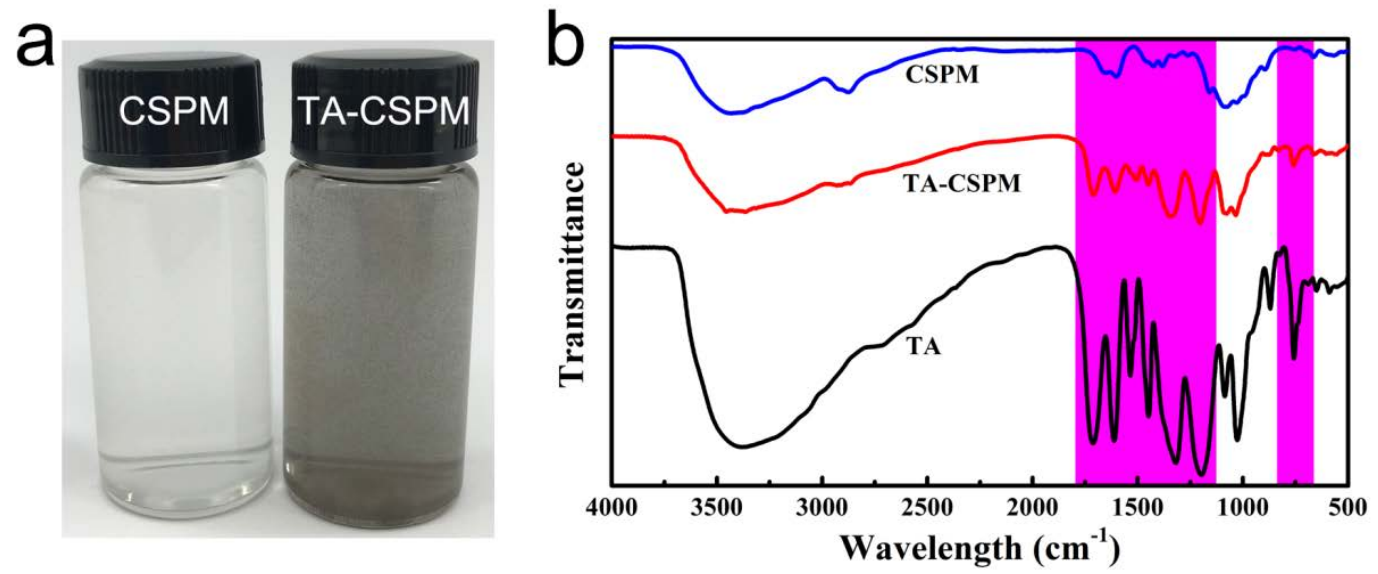

Figure S14. Color reaction (a) and FT-IR (b) of CSPM and TA-CSPM. The optical image is CSPM and TA-CSPM immersed in $0.1 \mathrm{M} \mathrm{AgNO}_{3}$ aqueous solution, respectively.

As shown in Figure S14a, color reaction was carried out to confirm the successful interfacial assembly between CSPM and tannic acid. The $\mathrm{AgNO}_{3}$ aqueous solution immersing CSPM (left) did not produce any visible discoloration. However, after treated with TA-CSPM (right), $\mathrm{AgNO}_{3}$ aqueous solution became brown from colorless. As shown in Figure S14b, as for CSPM, the bands at $\sim 1425 \mathrm{~cm}^{-1}$, and 
$\sim 1382 \mathrm{~cm}^{-1}$ due to the absorption of -CH2- groups, and the characteristic peaks at $1652 \mathrm{~cm}^{-1}$ and $1601 \mathrm{~cm}^{-1}$ belonged to -NH2 absorption. ${ }^{1}$ After assembling tannic acid onto CSPM, the spectrum of TA-CSPM revealed the peaks at $1701 \mathrm{~cm}^{-1}$ and $758 \mathrm{~cm}^{-1}$, which were attributed to the $\mathrm{C}=\mathrm{O}$ stretching vibration of aromatic esters and $\mathrm{C}=\mathrm{C}$ distortion vibration within benzene rings in TA, respectively. Furthermore, the peak at $1448 \mathrm{~cm}^{-1}$ was observed due to the in-plane bend of $\mathrm{C}-\mathrm{O}-\mathrm{H}$ in the hydroxyl group of TA. ${ }^{2}$
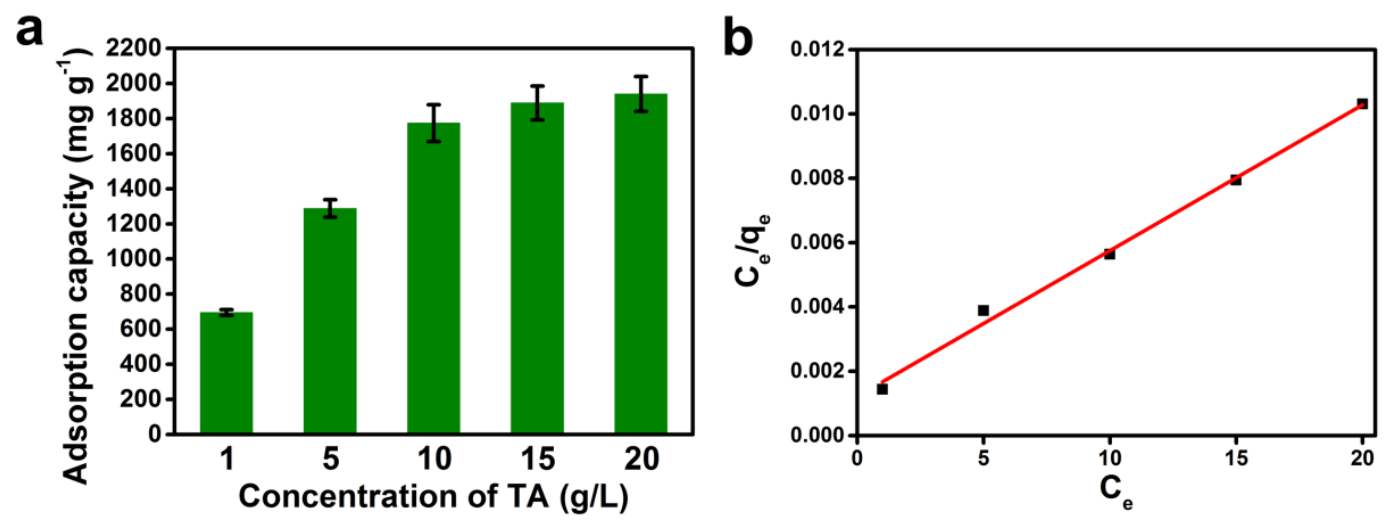

Figure S15. a) Effect of tannic acid concentration on adsorption capacity of tannic acid onto CSPM b) Langmuir adsorption isotherm model for interfacial assembly of tannic acid onto chitosan porous microspheres. That means all surface binding sites of CSPM were identical and each binding site could only hold one molecule, causing monolayer adsorption. 

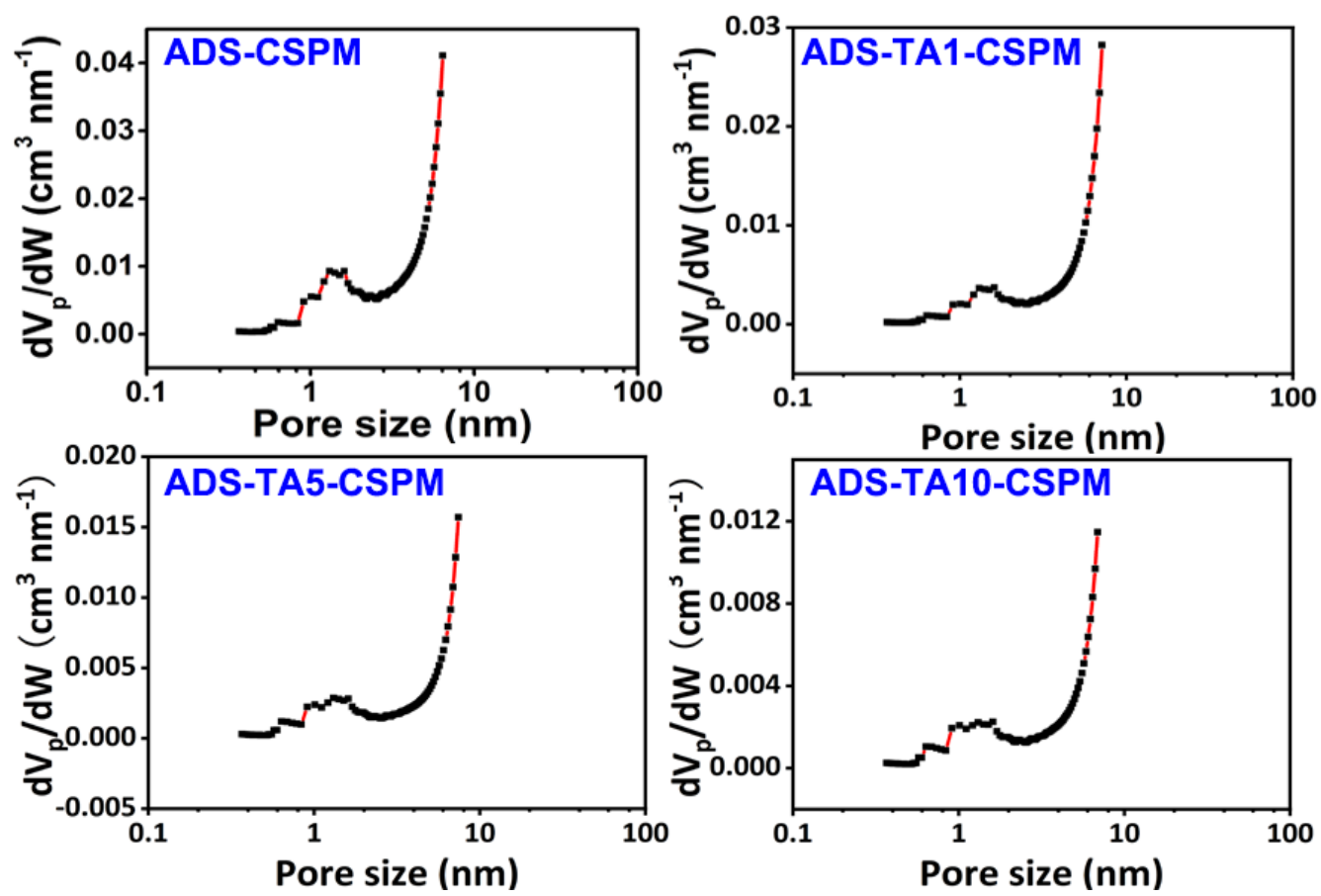

Figure S16. The pore size distribution of TA-CSPM vs adsorption capacity of tannic acid.
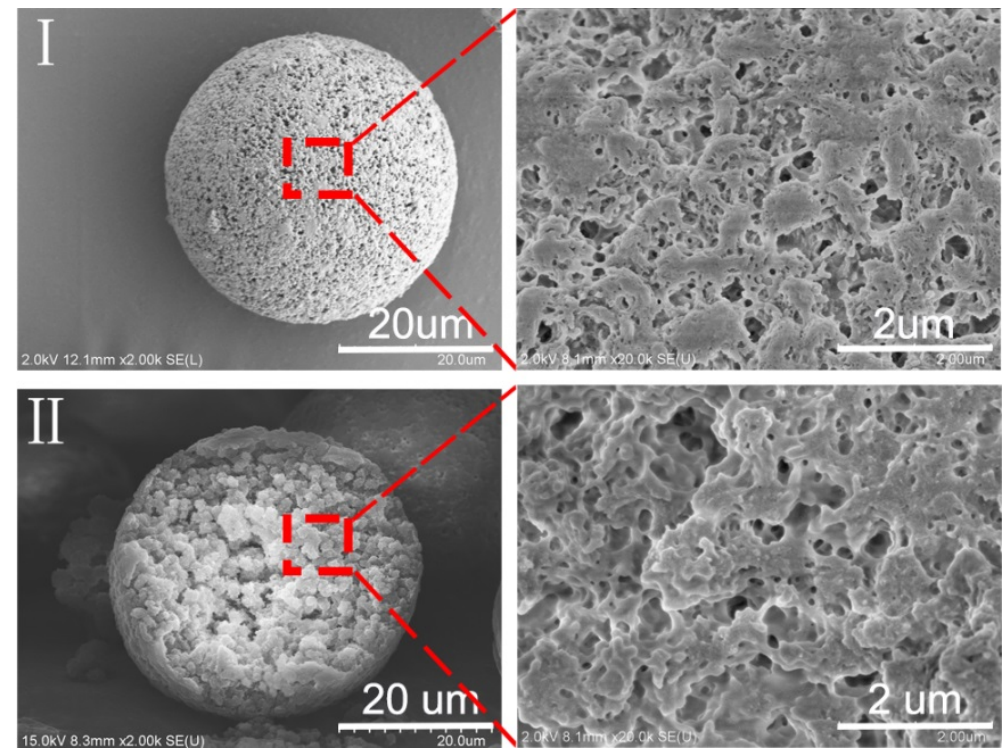

Figure S17. SEM images of a representative TA5-CSPM ( I ), and corresponding cross-section ( II ) of the TA5-CSPM, showing the TA-CSPM retain richly pore structure. 


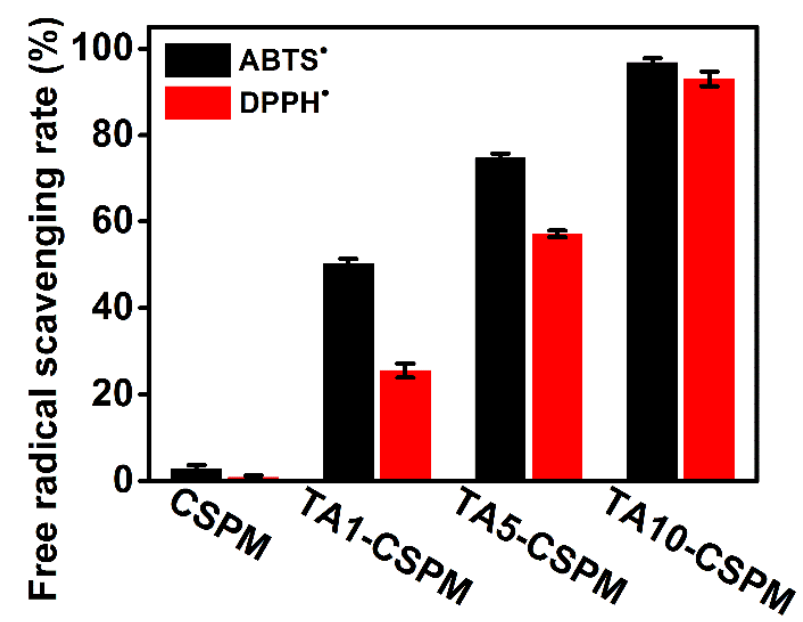

Figure S18. a) Radical scavenging rate of TA-CSPM vs adsorption capacity of tannic acid.

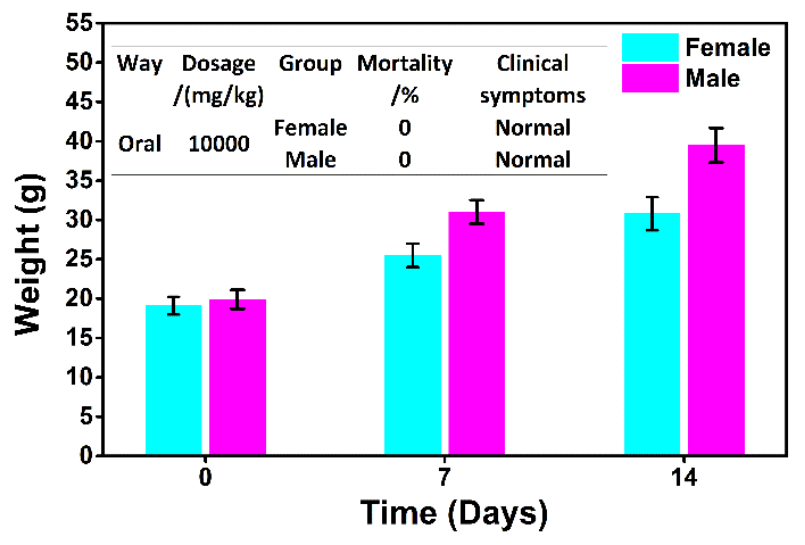

Figure S19. Results of acute oral toxicity test for mice with PPM, showing it is biocompatible.
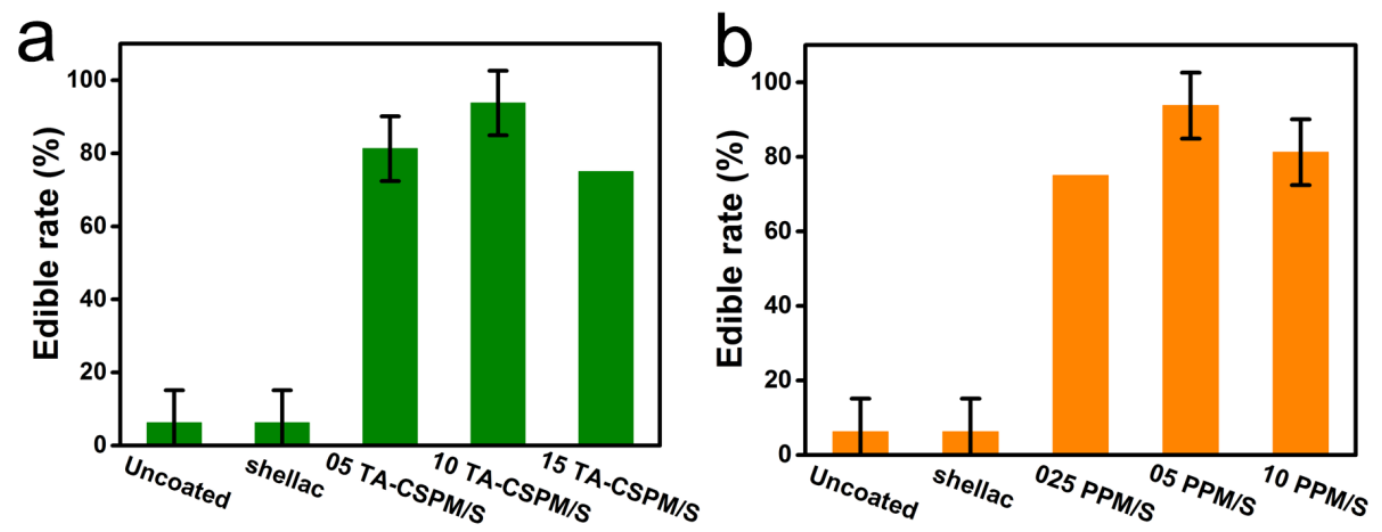

Figure S20. The edible rate of uncoated and coated mangoes after $10 \mathrm{~d}$ of storage.

a) Mangoes coated with TA-CSPM/shellac membranes. b) Mangoes coated with 
PPM/shellac membranes. The hybrid material-coated mangoes $(0.10 \% \quad(\mathrm{w} / \mathrm{v})$ TA-CSPM/shellac membrane and $0.05 \%(\mathrm{w} / \mathrm{v})$ PPM/shellac membrane) exhibit higher edible rate.

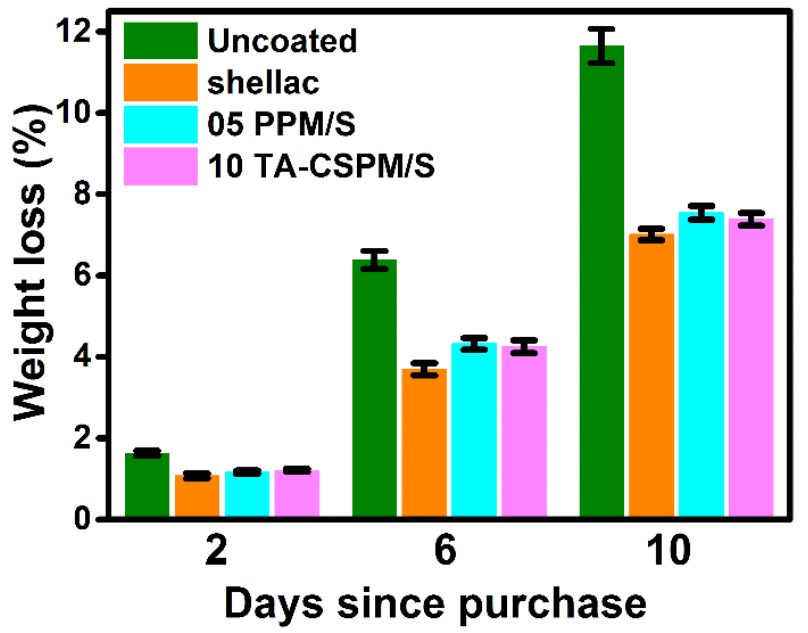

Figure S21. Weight loss of uncoated and coated mangoes during storage.
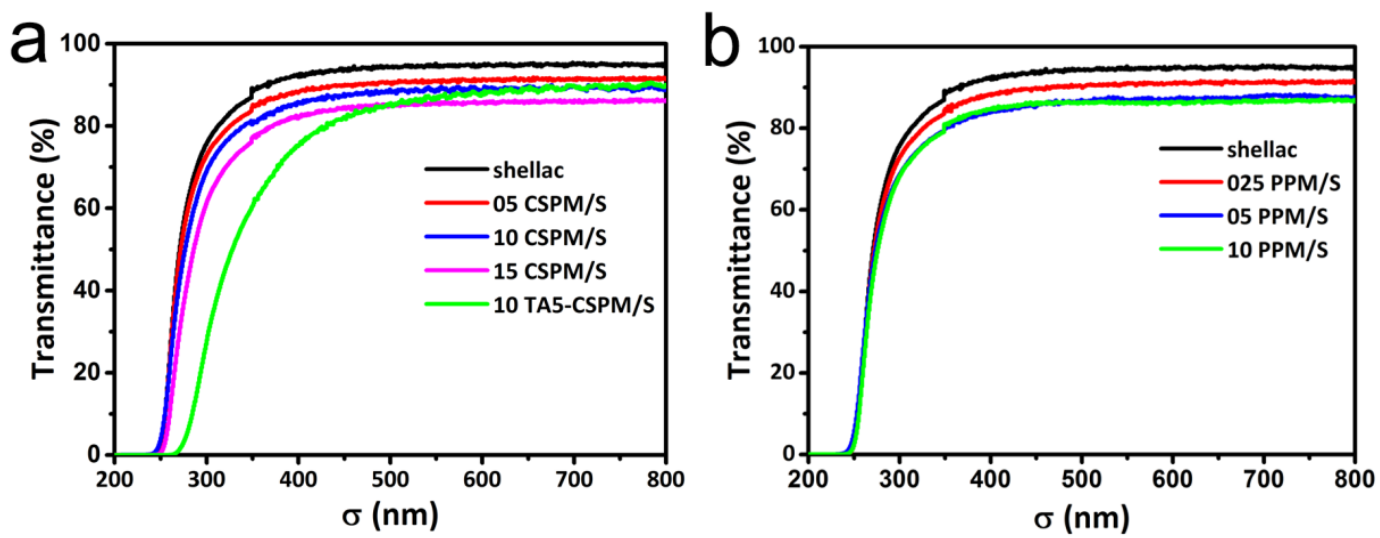

Figure S22. The transmittance of the hybrid materials. a) The hybrid membranes embedded with CSPM or TA5-CSPM. b) The hybrid membranes embedded with PPM. 

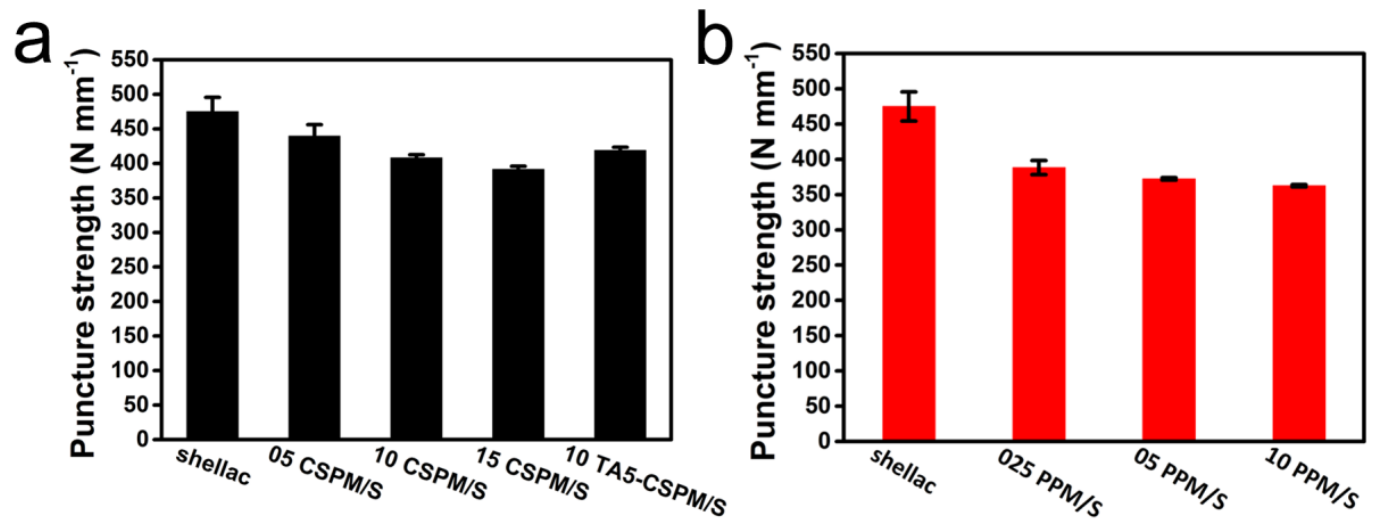

Figure S23. The puncture strength of hybrid membranes. a) The hybrid membranes embedded with CSPM or TA5-CSPM. b) The hybrid membranes embedded with PPM.
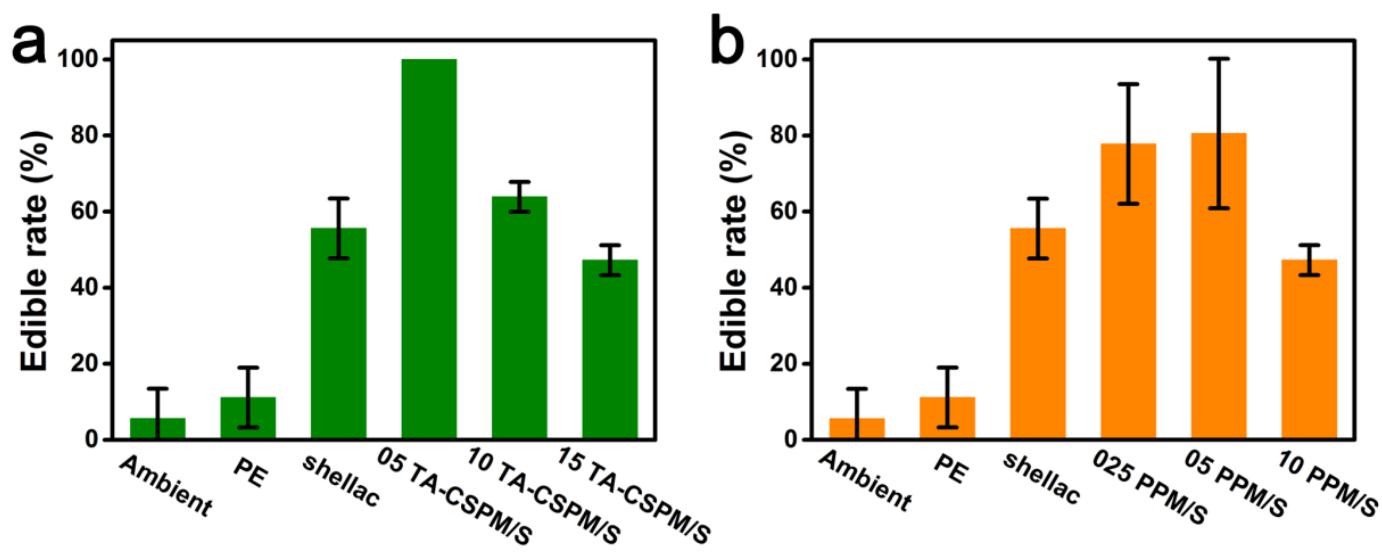

Figure S24. The edible rate of ambient (unpackaged) and packaged waxberries after $48 \mathrm{~h}$ of storage. a) Waxberries packaged with TA-CSPM/shellac membranes. b) Waxberries packaged with PPM/shellac membranes. The hybrid material-packaged waxberries (0.05\% (w/v) TA-CSPM/shellac membrane and 0.05\% (w/v) PPM/shellac membrane) exhibit higher edible rate. 


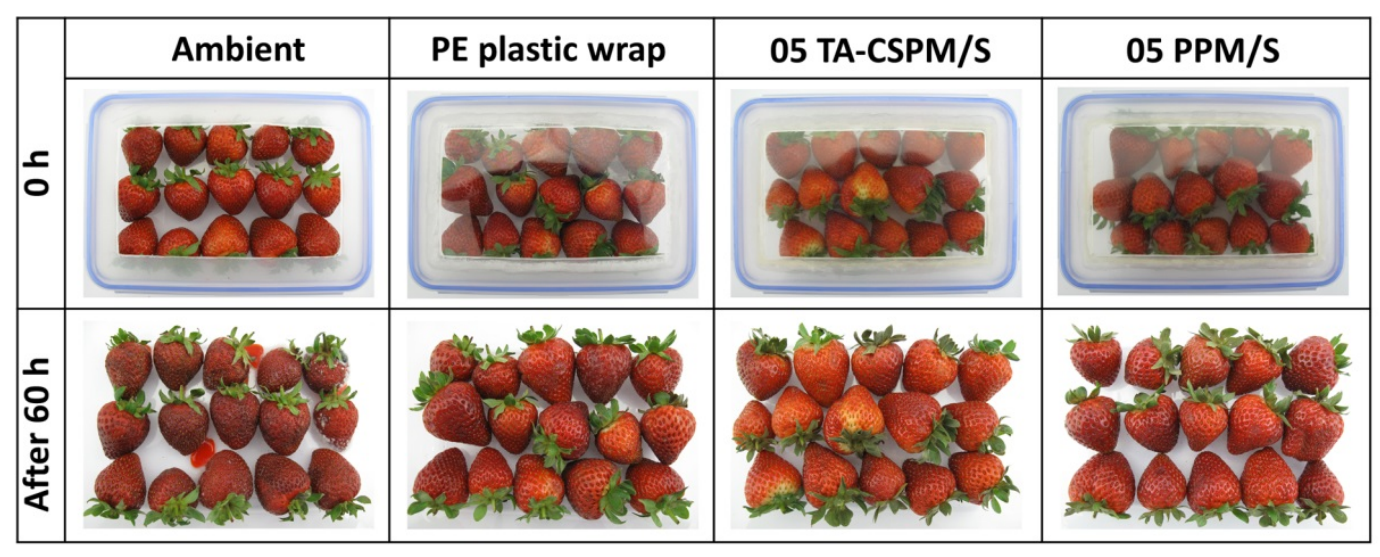

Figure S25. The photographs of ambient and packaged strawberries after $60 \mathrm{~h}$ of storage. The hybrid material-packaged strawberries $(0.05 \%(\mathrm{w} / \mathrm{v})$ TA-CSPM/shellac membrane and $0.05 \%(\mathrm{w} / \mathrm{v}) \mathrm{PPM} /$ shellac membrane) retain vivid appearance.
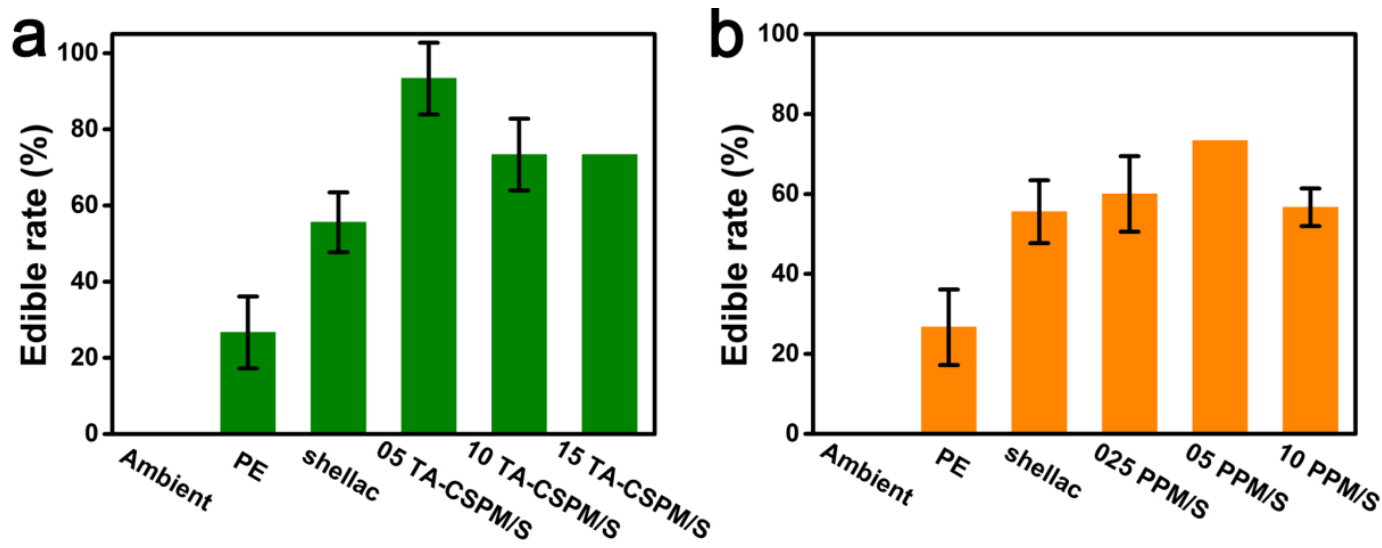

Figure S26. The edible rate of ambient and packaged strawberries after $60 \mathrm{~h}$ of storage. a) Strawberries packaged with TA-CSPM/shellac membranes. b) Strawberries packaged with PPM/shellac membranes. The hybrid material-packaged strawberries $\quad(0.05 \% \quad(\mathrm{w} / \mathrm{v}) \quad$ TA-CSPM/shellac membrane and $0.05 \% \quad(\mathrm{w} / \mathrm{v})$ PPM/shellac membrane) exhibit higher edible rate. 

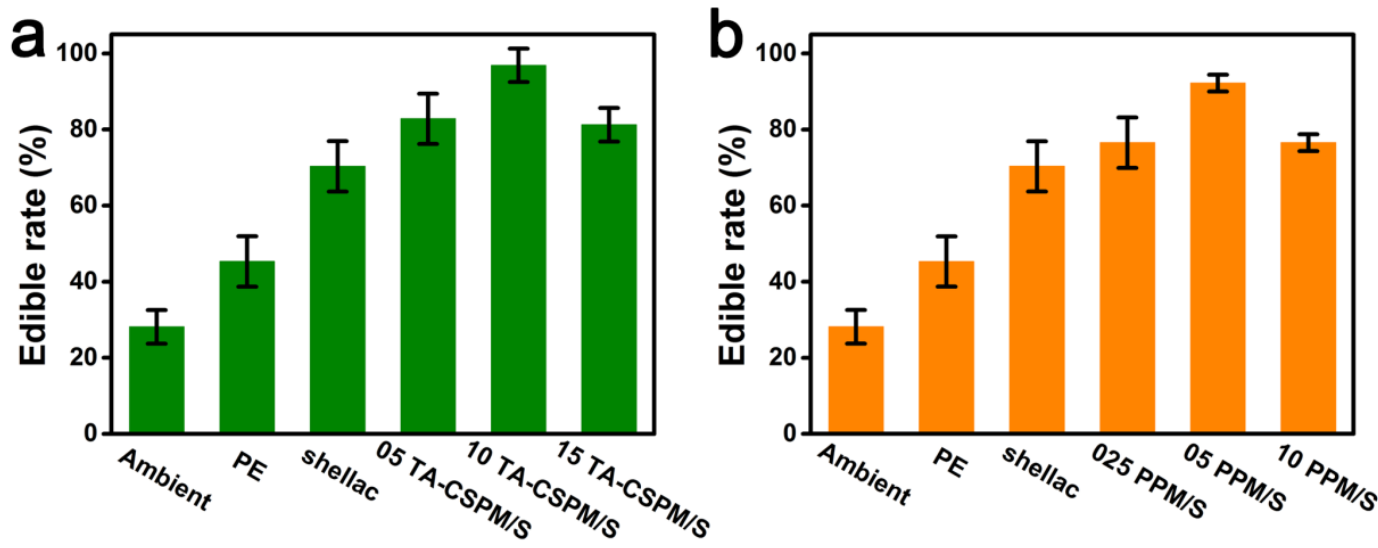

Figure S27. The edible rate of ambient and packaged cherries after $72 \mathrm{~h}$ of storage. a) Cherries packaged with TA-CSPM/shellac membranes. b) Cherries packaged with PPM/shellac membranes. The hybrid material-packaged cherries $(0.10 \%$ (w/v) TA-CSPM/shellac membrane and 0.05\% (w/v) PPM/shellac membrane) exhibit higher edible rate.
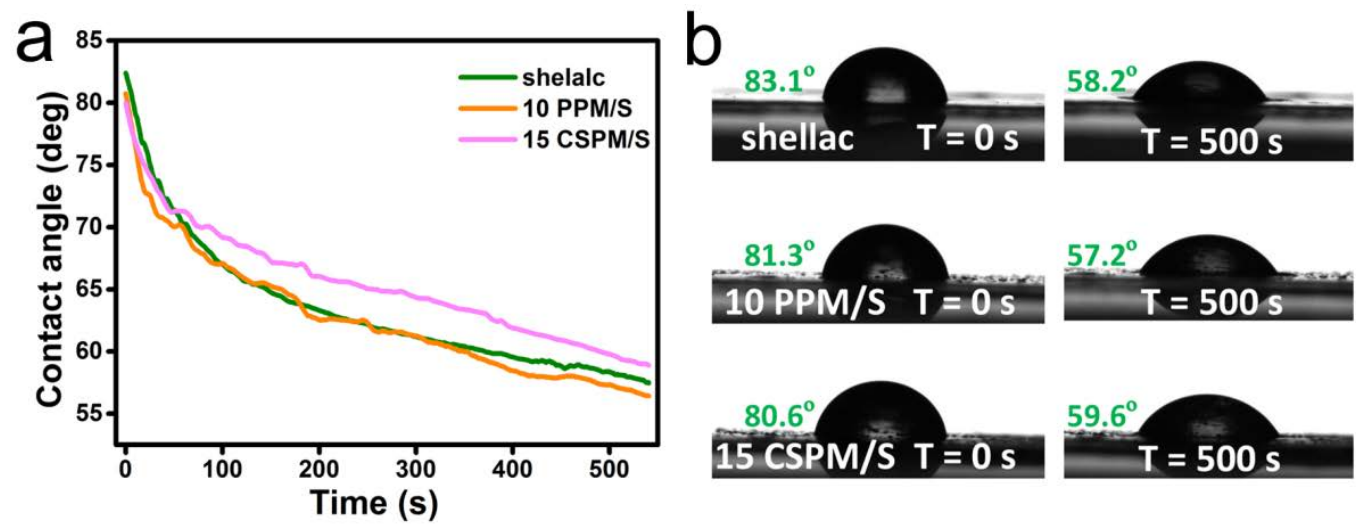

Figure S28. The contact angle of the hybrid materials. a) The decrease in contact angle with the time of the hybrid membranes. b) Optical images of the contact angle of the hybrid membranes. 


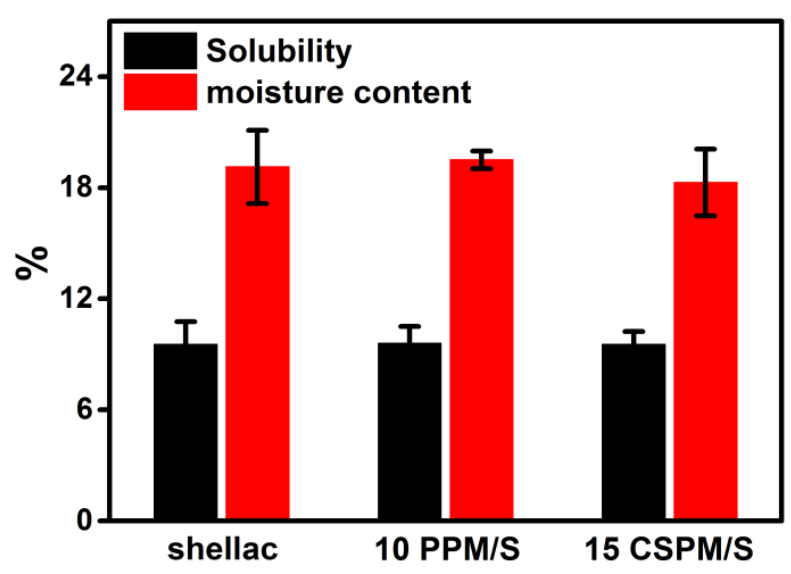

Figure S29. The solubility and moisture content of the hybrid materials.

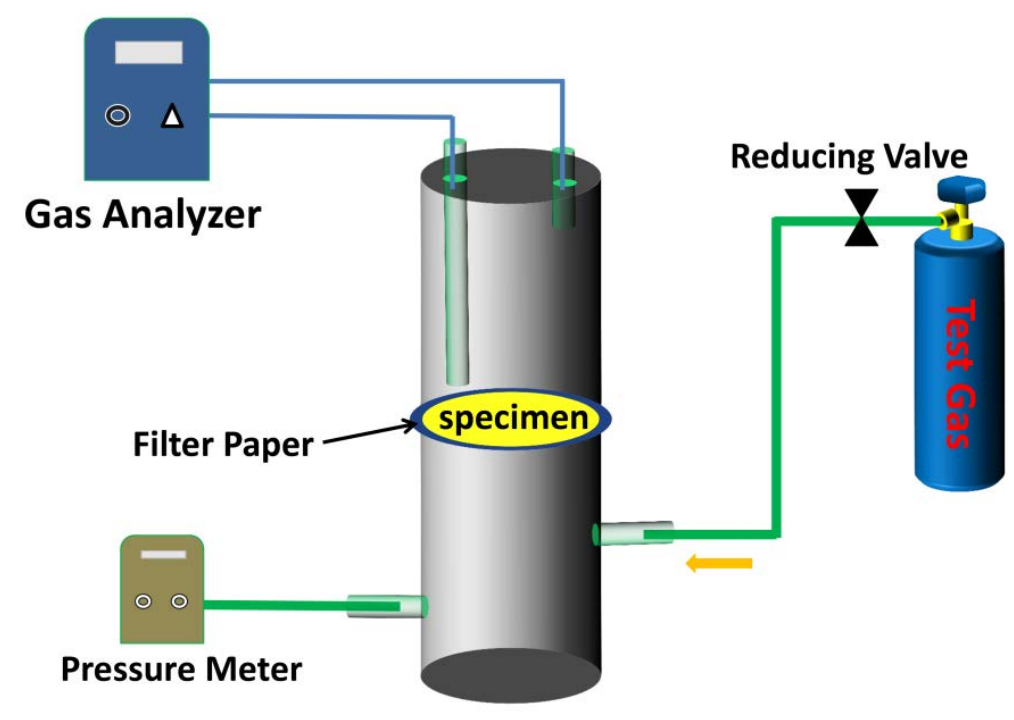

Figure S30. Scheme of the permeation system measuring the gas permeability of membranes.

Table S1. Pore structure parameters of CSPM and TA-CSPM by nitrogen gas adsorption

\begin{tabular}{ccccc}
\hline Sample & $\begin{array}{c}\mathrm{a}_{s, B E T} /\left(\mathrm{m}^{2}\right. \\
\left.\mathrm{g}^{-1}\right)\end{array}$ & $\mathrm{Vp} /\left(\mathrm{cm}^{3} \mathrm{~g}^{-1}\right)$ & $\begin{array}{c}\text { The average diameter of } \\
\text { pores/nm }\end{array}$ & $\begin{array}{c}\text { The middle } \\
\text { diameter of } \\
\text { pores } / \mathrm{nm}\end{array}$ \\
\hline CSPM & 62 & 0.0962 & 3.6 & 6.4 \\
TA1-CSPM & 32 & 0.0744 & 5.6 & 11.0 \\
TA5-CSPM & 22 & 0.0437 & 4.5 & 9.6 \\
TA10-CSPM & 17 & 0.0322 & 5.5 & 10.0 \\
\hline
\end{tabular}


Table S2. The intrinsic viscosity of the hybrid solvent

\begin{tabular}{ccccc}
\hline Sample & PEG1000 & Gelatin & Shellac & $\begin{array}{c}\text { Hybrid solvent } \\
\text { (Shellac (8 wt\%) + Gelatin (0.8 wt\%) } \\
\end{array}$ \\
& & & \\
\hline $\begin{array}{c}\text { Intrinsic } \\
\text { viscosity } \\
{[\eta]}\end{array}$ & 6.6 & 88.1 & 5.9 & 11.5 \\
\hline
\end{tabular}

\section{References}

1. Cai, B.; Zou, Q.; Zuo, Y.; Mei, Q.; Ma, J.; Lin, L.; Chen, L.; Li, Y. Injectable Gel Constructs with Regenerative and Anti-Infective Dual Effects Based on Assembled Chitosan Microspheres. ACS Appl. Mater. Interfaces 2018, 10, 25099-25112.

2. Wang, Y.; Li, J.; Li, B. Nature-Inspired One-Step Green Procedure for Enhancing the Antibacterial and Antioxidant Behavior of a Chitin Film: Controlled Interfacial Assembly of Tannic Acid onto a Chitin Film. J. Agric. Food Chem. 2016, 64, 5736-5741. 